\title{
Arginine Auxotrophs of Candida albicans Deficient in Argininosuccinate Lyase
}

\author{
By GWENDOLYN F. GIBBONS AND DEXTER H. HOWARD* \\ Department of Microbiology and Immunology, UCLA School of Medicine, Los Angeles, \\ California 90024, USA
}

(Received 11 July 1985; revised 2 September 1985)

\begin{abstract}
Auxotrophic mutants of Candida albicans FC18 were induced by a combination of treatments with nitrous acid and UV irradiation. Arginine $\left(\mathrm{Arg}^{-}\right)$, histidine ( $\left.\mathrm{His}^{-}\right)$and methionine/cysteine (Met $\mathrm{A}^{-}$) auxotrophs were recovered by this means. The $\mathrm{Arg}^{-}$auxotrophs lacked active argininosuccinate lyase (EC 4.3.2.1), the enzyme catalysing the final step in arginine biosynthesis. Thus the locus may be designated arg-4. The mutant strains bearing this mutation did not form germ tubes unless the germination medium contained arginine.
\end{abstract}

\section{INTRODUCTION}

Blastoconidia of the commensal fungus Candida albicans may initiate a hyphal form of growth by germination (Dabrowa \& Howard, 1983). Germ tube formation is fostered by a variety of environmental factors but an incubation temperature of $37^{\circ} \mathrm{C}$ is mandatory (Dabrowa \& Howard, 1983; Odds, 1979). Among amino acids that induce germination, those that enter the metabolism by conversion to 2-oxoglutarate are generally the most active (Dabrowa et al., 1976; Dabrowa \& Howard, 1983). A study of the role of amino acids in germ tube formation by $C$. albicans would be assisted by a collection of biochemically defined mutants.

Until recently the amictic C. albicans was assumed to be haploid. However, auxotrophic mutants were not readily available (Howard, 1985; Whelan et al., 1984) and several authors reported unsuccessful efforts to derive the customary diverse spectrum of such mutations by conventional techniques (Lingens \& Oltmanns, 1964; Jacobson \& Ayers, 1979; Olaiya \& Sogin, 1979; Whelan \& Magee, 1981; Whelan et al., 1980). The reason for this intractability is now widely acknowledged to be that most available isolates of $C$. albicans are diploid (Hubbard et al., 1985; Kakar \& Magee, 1982; Kakar et al., 1983; Olaiya \& Sogin, 1979; Poulter et al., 1981, 1982; Poulter \& Rikkerink, 1983; Howard, 1985) and that the isolation of certain mutants from $C$. albicans stocks derives from the rather large extent of natural heterozygosity among those diploids (Whelan et al., 1980; Whelan \& Magee, 1981; Whelan \& Soll, 1982).

In order to widen the spectrum of auxotrophs available for analysis, Kakar \& Magee (1982) and Kakar et al. (1983) devised a method of two-step mutagenesis. The first step is the mutagenic agent acting on homozygous loci; the second step induces mitotic recombination. Alternatively, the two steps may be combined into a single mutagenic procedure of unusual intensity (Kakar et al., 1983). We have adopted the technique of two-step mutagenesis in order to search for mutants of $C$. alhicans that are auxotrophic for amino acids in the glutamate family (alanine, arginine, glutamic acid, histidine, ornithine and proline), which are among the most vigorous amino acid inducers of germination of the fungus (Dabrowa \& Howard, 1983; Howard, 1985).

Abbreviations: GPA, glucose/peptone agar; MIN, yeast nitrogen base without amino acids or ammonium sulphate: YEPD, yeast extract/peptone/dextrose; YNBMM, yeast nitrogen base without amino acids. 
The FC18 strain of C. albicans was chosen for our work because of the considerable amount of information about it already at hand (Kakar \& Magee, 1982; Kakar et al., 1983; Whelan et al., 1980; Whelan \& Magee, 1981). In the course of the study we obtained arginine, histidine and methionine/cysteine auxotrophs and icientified the biochemical defect which determined arginine auxotrophy.

\section{METHODS}

Organism. Candida albicans FC18 was obtained from Dr P. T. Magee, Michigan State Laboratory, East Lansing, Mich., USA. Stock cultures were preserved in the Fungus Collection, University of California, Los Angeles, Calif., USA. Working cultures were maintained on glucose/peptone agar (GPA) in a refrigerator and were subcultured every month.

Media. GPA contained 2\%(w/v) Bacto-Dextrose (Difco), $1 \%$ (w/v) Bacto-Peptone (Difco) and 2\%(w/v) BactoAgar (Difco). Yeast extract/peptone/dextrose (YEPD) agar contained $1 \%$ (w/v) Bacto-Yeast Extract (Difco), $2 \%$ (w/v) Bacto-Peptone (Difco), 2\% (w/v) Bacto-Dextrose (Difco) and 2\%(w/v) Bacto-Agar (Difco). Yeast nitrogen base without amino acids (YNBMM) was prepared in accordance with the manufacturer's instructions (Difco) as was yeast nitrogen base without amino acids or ammonium sulphate (MIN). LBC synthetic medium (Lee et al., 1975 ) consisted of $\left(\mathrm{NH}_{4}\right)_{2} \mathrm{SO}_{4}, 5 \mathrm{~g} ; \mathrm{MgSO}_{4}, 7 \mathrm{H}_{2} \mathrm{O}, 0 \cdot 2 \mathrm{~g} ; \mathrm{K}_{2} \mathrm{HPO}_{4}, 2.5 \mathrm{~g}$; NaCl, $5 \mathrm{~g}$; glucose, $12.5 \mathrm{~g}$; alanine, $0.5 \mathrm{~g}$; leucine, $1.3 \mathrm{~g}$; lysine, $1 \mathrm{~g}$; methionine, $(\cdot 1 \mathrm{~g}$; ornithine, $0.0714 \mathrm{~g}$; phenylalanine, $0.5 \mathrm{~g} ;$ proline, $0.5 ; \mathrm{g}$; threonine, $0.5 \mathrm{~g}$; biotin (Nutritional Biochemicals Corp.) $1 \mathrm{mg}$; distilled water, 1 litre. The biotin was filtersterilized and added to the other ingredients after they had been autoclaved at $110^{\circ} \mathrm{C}$ for $20 \mathrm{~min}$. All chemicals, including the amino acids used to define the auxotrophs, were purchased from Sigma, Calbiochem or Eastman Kodak.

Mutagenesis and growth conditions. A two-step mutagenesis procedure devised by Kakar et al. (1983) was used to derive the mutants. The procedure involved mutagenesis with nitrous acid (step 1) followed by UV irradiation (step 2) to induce mitotic crossing over.

Cells of C. albicans were grown at room temperature on YNBMM plates overnight. The cells were harvested in distilled water, washed once by centrifugation and resuspended in $0.2 \mathrm{M}$-sodium acetate buffer ( $\mathrm{pH} 5 \cdot 0$ ) to a density of $2 \times 10^{7}$ cells $\mathrm{ml}^{-1}$. Equal volumes of the suspended cells and $0.4 \mathrm{M}$-sodium nitrite made up in sodium acetate buffer were incubated at room temperature and the reaction was stopped at various time intervals by dilution $(1: 10)$ in $0 \cdot 1 \mathrm{M}$-sodium phosphate buffe $\mathrm{(}(\mathrm{pH} 8 \cdot 0)$. Cells were diluted further in distilled water and plated on GPA to determine the percentage of survivors. Preliminary experiments established that 15 min incubation of cells in sodium nitrite ( $0.2 \mathrm{M})$ under these conditions resulted in approximately $54 \%$ survival of cells and this time was chosen for the mutagenesis step.

The entire volume of cells exposed to sodium nitrite was poured into a plastic Petri dish and exposed for $15 \mathrm{~s}$ to UV light at a distance of $18 \mathrm{~cm}$ from the source (34\% survivors; overall yield about $15 \%$ survivors). The light source was a GE-G875 UV tube (General Electric).

Isolation and testing of mutants. The cells from the nitrous acid-UV combination treatment were diluted in distilled water immediately after UV irradiation and plated on GPA. The plates were incubated at room temperature for $7 \mathrm{~d}$. Colonies were replica plated onto GPA and YNBMM. Mutants were selected by preliminary testing for auxotrophy in accordance with the pattern method devised by Holliday (1956). The nutrient mixtures were incorporated into MIN agar plates. Amino acid auxotrophs were selected by subculture of indicated auxotrophs to MIN agar plates supplemented with single amino acids at a concentration of $0 \cdot 2 \mathrm{mM}$.

Determination of the biochemical defect in the arginine mutants. The site of the lesions in selected arginine mutants was determined by growing subcultures of isolated clones on MIN agar plus the intermediates of the arginine biosynthetic pathway (Fig. 1).

The enzymes were analysed as follows. Exponential phase cells, grown in liquid YNBMM plus arginine at room temperature on a rotary shaker, were harvested by centrifugation, washed and resuspended in extraction buffer $\left(0.02 \mathrm{M}-\mathrm{KH}_{2} \mathrm{PO}_{4}\right.$ and $\left.0.02 \mathrm{M}-\mathrm{Na}_{2} \mathrm{HPO}_{4} ; \mathrm{pH} 7.5\right)$. Cell-free extracts were made by vortexing the cells in four $30 \mathrm{~s}$ pulses with $0.45 \mathrm{~mm}$ glass beads. All procedures were done on ice. Crude extracts were partially purified by $\left(\mathrm{NH}_{4}\right)_{2} \mathrm{SO}_{4}$ fractionation (Fincham \& Boylen, 1957). The fractionated extracts were examined for argininosuccinate lyase (EC 4.3.2.1) activity by the method of Campanini et al. (1970). Protein was determined by the Lowry method with bovine serum albumin as the standard.

Germination assays. The parental FC18 strain was grown on YNBMM and each of the auxotrophs or fusion products (see next section) was grown on MIN agar supplemented with the required amino acid. The cultures were incubated at room temperature overnight. Cells were harvested in distilled water, washed once by centrifugation and resuspended to a concentration of $1 \times 10^{7}$ cells ml-1. The media used to foster germination included: (i) single inducers (L-arginine, L-glutamic acid, L-proline, L-leucine and $\mathrm{N}$-acetylglucosamine) at a concentration of $0.2 \mathrm{~mm}$ in 0.033 M-sodium phosphate buffer ( $\mathrm{pH} \mathrm{7.0)}$; (ii) LBC medium; and (iii) LBC medium supplemented with $0.2 \mathrm{~mm}$-L-arginine. About $1 \times 10^{\circ}$ cells $\mathrm{ml}^{-1}$ were incubated in $1 \mathrm{ml}$ of each medium for $3 \mathrm{~h}$ at $37^{\circ} \mathrm{C}$. The tubes 
were agitated gently on a Multipurpose Rotator, model 150 (Scientific Industries). A loopful of the cells was removed from each of the media, placed on a glass slide and examined microscopically. The percentage of cells with germ tubes was determined by counting 100 cells.

Preparation of spheroplasts. Cells of the auxotrophs were grown in YEPD broth overnight at $37^{\circ} \mathrm{C}$. The exponential phase cells were harvested, washed in distilled water and resuspended in spheroplast buffer $(1.0 \mathrm{M}-$ sorbitol in $0.1 \mathrm{M}$-potassium phosphate buffer, $\mathrm{pH} \mathrm{7.5)}$ at a concentration of $250 \mathrm{mg}$ cells (wet wt) $\mathrm{ml}^{-1} . \beta$ Mercaptoethanol and Zymolyase 5000 (Miles Laboratories) were added to a concentration of $2 \cdot 5 \mu \mathrm{l}(\mathrm{ml} \text { mixture })^{-1}$ and $2.5 \mathrm{mg}$ (g wet wt cells) ( $^{-1}$, respectively, and the mixtures were incubated at $37^{\circ} \mathrm{C}$ with slow stirring for 1 to $2 \mathrm{~h}$. The extent of spheroplast formation was tested at intervals by checking lysis in $5 \%(\mathrm{w} / \mathrm{v}) \mathrm{SDS}$. When $95 \%$ of the cells had converted into spheroplasts, $1.5 \mathrm{ml}$ spheroplast buffer was added for every $1 \mathrm{ml}$ of mixture. Spheroplasts were centrifuged at $620 \mathrm{~g}$ and gently washed five times in $10 \mathrm{ml}$ spheroplast buffer. Spheroplasts were finally suspended by very gentle shaking in $10 \mathrm{ml}$ spheroplast buffer and stored overnight at $4{ }^{\circ} \mathrm{C}$.

Spheroplast fusion and regeneration. Complementation was studied by parasexual methods involving spheroplast fusion (Fournier et al., 1977; Evans et al., 1982; Pesti \& Ferenczy, 1982; Poulter et al., 1981). Approximately $5 \times 10^{8}$ spheroplasts from each type were mixed and left at room temperature for $15 \mathrm{~min}$. The mixtures were centrifuged at $620 \mathrm{~g}$ and the pellets were resuspended gently in $10 \mathrm{ml}$ fusion mixture $[40 \%(\mathrm{w} / \mathrm{v})$ polyethylene glycol 3350 and $10 \mathrm{mM}-\mathrm{CaCl}_{2}$ in $\left.10 \mathrm{mM}-\mathrm{Tris} / \mathrm{HCl}(\mathrm{pH} 7 \cdot 5)\right]$. After $60 \mathrm{~min}$ incubation at room temperature, the cells were pelleted by centrifugation at $600 \mathrm{~g}$ and the pellets resuspended in $10 \mathrm{ml}$ spheroplast buffer.

A $1 \mathrm{ml}$ sample of the diluted fusion aggregate $\left(1-2 \times 10^{7}\right.$ spheroplasts $)$ was mixed with $100 \mathrm{ml}$ of a regeneration medium (MIN with $1.0 \mathrm{M}$-sorbitol, $0.2 \mathrm{mM}$-arginine, $10 \mu \mathrm{g}$ tetracycline $\mathrm{ml}^{-1}$ and $3 \%$ agar) kept at $45-50{ }^{\circ} \mathrm{C}$. The mixtures were immediately poured into Petri dishes and left at room temperature for 1 to $2 \mathrm{~d}$. The plates were then shifted to $37^{\circ} \mathrm{C}$ for an additional incubation for 1 to $2 \mathrm{~d}$. Regeneration was efficient $(82 \%)$. Colonies were picked to YEPD agar plates for replica plating onto appropriate media to determine the auxotrophic requirements.

\section{RESULTS}

\section{Isolation of auxotrophs}

Initial experiments were done to determine the optimum concentration of sodium nitrite together with the time of exposure which would yield $50 \%$ survival and the time of exposure to UV irradiation which resulted in 50\% survival (Kakar \& Magee, 1982; Kakar et al., 1983; P. T. Magee, personal communication). Approximately $1.5 \%$ of the population that survived the two treatments were mutants. Survivors grew slowly and required a minimum of $7 \mathrm{~d}$ to grow out. Auxotrophs were identified as those colonies that failed to grow on YNBMM, but grew normally on GPA. Of the slow-growing survivors, three classes of auxotrophs were identified: arginine $\left(\mathrm{Arg}^{-}\right)$, histidine (His $\left.{ }^{-}\right)$and methionine/cysteine (MetA-) auxotrophs. Auxotrophy was confirmed by determining growth on minimal media supplemented with individual amino acids at a concentration of $0 \cdot 2 \mathrm{~mm}$ (Holliday, 1956).

The Met $\mathrm{A}^{-}$auxotrophs are commonly encountered in the FC1 8 strain of $C$. albicans and are considered to arise from UV-induced segregation of a heterozygous locus (Whelan et al., 1980; Whelan \& Magee, 1981). Our isolate was not characterized further. The two $\mathrm{Arg}^{-}$auxotrophs, labelled FC18-1 and FC18-6, were purified by several passages on MIN + arginine to ensure that a single auxotrophic type was being studied. The isolates grew in whole colonies only on complete media or on plates supplemented with arginine. The His ${ }^{-}$auxotroph, labelled FC18-3, was used in complementation studies but the site of the lesion was not identified.

The spontaneous reversion rate was established by plating $10^{9}$ cells on YNBMM and counting the number of colonies that grew. Each revertant was retested and confirmed by streaking on YNBMM. The spontaneous backward rate of mutation for the arginine auxotroph FC18-1 was four per $10^{9}$ cells and that for FC18-6 was one per $10^{9}$ cells. The back mutation rates for the histidine and methionine/cysteine mutants were not determined. This low reversion rate makes these $\mathrm{Arg}^{-}$mutants suitable subjects for studies on transformation of $C$. albicans.

\section{Identification of the lesion in the $\mathrm{Arg}^{-}$isolates}

The arginine biosynthetic pathway described for fungi (Rhodes \& Howard, 1980) is shown in Fig. 1. The intermediates shown were used to determine the site of the mutation in the $\mathrm{Arg}^{-}$ isolates. The two mutants (FC18-1 and FC18-6) and their parent $\mathrm{FC} 18$ were inoculated on YNBMM with and without arginine, and onto YNBMM supplemented with the intermediates ornithine, citrulline and argininosuccinate. The arginine requirement of the two mutant strains 

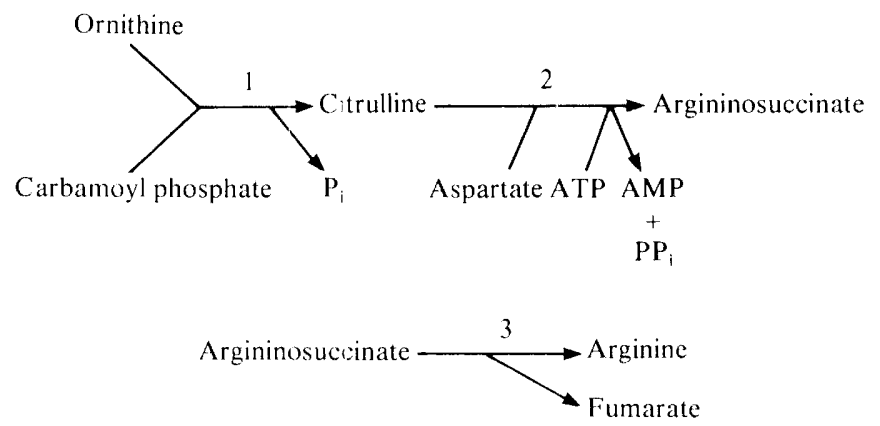

Fig. 1. Pathway of arginine biosynthesis. The numbers denote enzymes: 1, ornithine carbamoyltransferase (carbamoyl-phosphate:L-ornithine carbamoyltransferase; EC 2.1.3.3): 2, argininosuccinate synthase (L-citrulline:L-aspartate ligase, AMP-forming; FC 6.3.4.5); 3, argininosuccinate lyase (Largininosuccinate arginine-lyase; EC 4.3.2.1).

could not be fulfilled by any of the said precursors, indicating that the probable site of the lesion was the terminal step in the pathway, which is catalysed by argininosuccinate lyase.

The site of the lesion was confirmed by assay for argininosuccinate lyase. Crude cell-free extracts of both mutants and the parent were prepared from exponential phase cells in Y NBMM supplemented with arginine. The extracts were partially purified by the $\left(\mathrm{NH}_{4}\right)_{2} \mathrm{SO}_{4}$ precipitation protocol (Fincham \& Boylen, 1957). This method removes $>80 \%$ of the arginase, as well as free arginine, from the extracts and allows a colorimetric procedure which measures arginine production from argininosuccinate to be used for the enzyme assay (Campanini et al., 1970). The extracts from the parent FC18 strain contained active argininosuccinate lyase [6700 $\mathrm{U}$ (mg protein $)^{-1} ; 1$ unit forms $1 \mu$ mol arginine from argininosuccinate $\mathrm{h}^{-1}$ ] whilst no such activity was detectable in the FCl8-1 or FC18-6 mutants. These results confirm that the auxotrophy of the $\mathrm{Arg}^{-}$mutants was due to their failure to produce active argininosuccinate lyase. Thus the locus affected in FC 18-1 and FC18-6 should be designated arg-4, in accordance with the suggestion of Poulter \& Rikkerink (1983) that the designation of loci in Candida be made to correspond to those of loci in Saccharomyces.

\section{Germination of auxotrophs}

Amino acids that enter metabolism by conversion to glutamate promote more filamentation, on average, than other groups of amino acids (Dabrowa \& Howard, 1981, 1983). Among the glutamate family arginine, glutamic acid and proline are the most active (Dabrowa et al., 1976). The $\mathrm{Arg}^{-}$auxotrophs along with the His ${ }^{-}$auxotroph were chosen for germination studies in various media that are conducive to germ tube formation (Table 1). The parental strain germinated well in LBC medium and reasonably well in buffer with single amino acids or $\mathrm{N}$ acetylglucosamine. However, the $\mathrm{Arg}^{-}$strains would germinate only in media in which the specific defect was redressed. Thus in spite of the fact that LBC medium contains proline, a vigorous inducer of germination, the medium would not support germination of the $\mathrm{Arg}^{-}$or His $^{-}$mutants.

\section{Complementation between arginine and histidine auxotrophs and germination of fusion products}

The optimum time for spheroplast formation with Zymolyase 5000 varied from 1 to $2 \mathrm{~h}$ for strain $\mathrm{FC} 18$ and for each of the auxotrophs. Because of these variations, incubation times were monitored during each experiment.

One $\mathrm{Arg}^{-}$and the $\mathrm{His}^{-}$auxotroph were selected for complementation studies. Three examples of prototrophic fusion products (arbitrarily labelled FP10, FPI6 and FP18) derived from regenerated spheroplasts were selected for germination studies. The ability of cells of the fusion products to germinate was assessed in the same media as those used to test the germination of the auxotrophs. The prototrophic fusion products from the cross $\mathrm{FC} 18-3\left(\mathrm{His}^{-}\right)$and $\mathrm{FC} 18-6\left(\mathrm{Arg}^{-}\right)$ germinated to about the same degree in the various media as did the parent FC18 (Table 1). 
Table 1. Germination of strain FC18, and arginine and histidine auxotrophs and certain auxotrophic deritatives

\begin{tabular}{|c|c|c|c|c|c|c|c|}
\hline \multirow[b]{3}{*}{$\begin{array}{l}\text { Germination } \\
\text { medium }\end{array}$} & \multicolumn{7}{|c|}{ Percentage germination } \\
\hline & \multirow[b]{2}{*}{$\begin{array}{l}\text { Parent } \\
\text { FC18 }\end{array}$} & \multicolumn{3}{|c|}{ Auxotrophs } & \multicolumn{3}{|c|}{ Fusion products } \\
\hline & & $\mathrm{FCl} 8-1$ & $\overbrace{\mathrm{FC}} 18-6$ & $\overline{F C} 18-3$ & FPIO & $\overbrace{\mathrm{FP} 16}$ & FP18 \\
\hline L-Arginine* & $58 \cdot 6$ & $31 \cdot 2$ & $38 \cdot 6$ & $6 \cdot 0$ & $40 \cdot 5$ & $55 \cdot 0$ & $66 \cdot 0$ \\
\hline L-Glutamic: acid* & $40 \cdot 8$ & 1.0 & $1 \cdot 0$ & $5 \cdot 5$ & ND & $73 \cdot 0$ & $68 \cdot 0$ \\
\hline L-Proline* & $64 \cdot 5$ & $2 \cdot 0$ & $0 \cdot 0$ & $3 \cdot()$ & $75 \cdot 5$ & $65 \cdot 5$ & $57 \cdot 5$ \\
\hline$N$-Acetylglucosamine* & $70 \cdot 5$ & $1 \cdot 5$ & $0 \cdot 6$ & $1 \cdot 3$ & $96 \cdot 0$ & $75 \cdot 0$ & $72 \cdot 0$ \\
\hline L.BC medium & 84.9 & $2 \cdot 2$ & $0 \cdot 2$ & $6 \cdot 0$ & $89 \cdot 5$ & $71 \cdot 5$ & $76 \cdot 0$ \\
\hline LBC plus L-arginine & $89 \cdot 3$ & 820 & $77 \cdot 8$ & $6 \cdot 5$ & $92 \cdot 0$ & $89 \cdot 5$ & $85 \cdot 0$ \\
\hline
\end{tabular}

\section{DISCUSSION}

Recognition of the fact that most clinical isolates and many laboratory stock cultures of $C$. albicans are diploid has led to techniques designed to render homozygous certain naturally occurring heterozygous mutants or to induce mutations that are revealed by mitotic crossing over (Kakar \& Magee, 1982; Kakar et al., 1983). In keeping with the experience of Whelan et al. (1980), short term exposure (15 s) of strain FC18 to UV irradiation resulted in isolation of methionine/cysteine mutants $\left(\mathrm{MetA}^{-}\right)$. But the two-step mutagenesis procedure with nitrous acid and UV irradiation provided several $\mathrm{Arg}^{-}$and $\mathrm{His}^{-}$mutants which were among those sought for our studies on germination of blastoconidia of $C$. albicans (see Introduction).

The FC18-1 and FC18-6 mutants could not process the intermediates in arginine biosynthesis to the final product arginine. The defect was confirmed by showing that both mutants lacked active argininosuccinate lyase, the enzyme catalysing the final step in arginine biosynthesis. Such a mutation is analogous to the arg-10 mutation in Neurospora crasa (Esser \& Kuenen, 1967) and to the $\arg A$ mutation in Aspergillus nidulans (Cybis et al., 1972). The locus should be designated $\arg -4$ in C. alhicans in accordance with the suggestion of Poulter \& Rikkerink (1983) that designation of loci in Candida be made to correspond to those of loci in Saccharomyces.

The auxotrophic mutants did not germinate even in the presence of strong inducers of germination such as $\mathrm{N}$-acetylglucosamine or proline. The $\mathrm{Arg}^{-}$auxotrophs could be induced to germinate only on media containing arginine (Table 1). As expected, the prototrophic complementation products germinated in the same sorts of media as did the parental FC18 strain. In Neurospora a large number of auxotrophic mutants have been tested for the ability of their conidia to germinate (Schmit \& Brody, 1976). None of the auxotrophs formed colonies on minimal media but most of the strains did form germ tubes. Interestingly, those auxotrophs that failed to germinate had defects in the synthesis of aromatic amino acids or basic amino acids (arginine, lysine and histidine). In addition, sporulation defects have been described in arginine auxotrophs of $A$. nidulans (Serlupi-Crescenzi et al., 1983).

The results from the complementation studies affirmed that the rate of occurrence of prototrophs far exceeded the rate of spontaneous back mutation. In these studies singly auxotrophic mutants were used in the spheroplast fusions. The use of doubly auxotrophic strains allows for more detailed sorts of genetic analyses (Kakar et al., 1983) but our goal was simple restoration of germination capacity by complementation of the arginine marker.

This investigation was supported by Public Health Service grant AI-16252 from the National Institute of Allergy and Infectious Diseases, NIH, Bethesda, Md, USA. During the preparation of the manuscript, one of us (D.H.H.) was the recipient of a grant from the Universitywide Task Force on AIDS, University of California, for work on blastoconidial germination by Candida albicans. We are grateful to Ms Lois Howard for her care in 
preparing the manuscript. This is publication no. 85 of the Collaborative California Universities-Mycology Research Unit (CCU-MRU).

Data presented in this report were part of a thesis presented by G.F.G. to the Department of Microbiology, California State University, Long Beach, Calif., in partial fulfillment of the requirements for the degree Master of Science.

\section{REFERENCES}

Campanini, R. Z., Tapia, R. A., Sarnat, W. \& NATELSON, S. (1970). Evaluation of serum argininosuccinate lyase (ASAL) concentrations as an index to parenchymal liver disease. Clinical Chemistry 16, 44 53.

Cybis, J., Piotrowska, M. \& Weglenski, P. (1972). The genetic control of the arginine pathways in Aspergillus nidulans mutants blocked in arginine biosynthesis. Acta microbiologia polonica Series A 4 , 163-169.

Dabrowa, N. \& Howard, D. H. (1981). Proline uptake in Candida alhicans. Journal of General Microbiology 127, 391-397.

Dabrowa, N. \& Howard, D. H. (1983). Blastoconidium germination. In Fungi Pathogenic for Humans and Animals, part A, pp. 525-545. Edited by D. H. Howard. New York: Marcel Dekker.

Dabrowa, N., TaXer, S. S. S. \& Howard, D. H. (1976). Germination of Candida albicans induced by proline. Infection and Immunity 13, 830-835.

EsSER, K. \& Kuenen, R. (1967). Genetics of Fungi, pp. 356-372. New York: Springer-Verlag.

Evans, K. O., AdeniJi, A.\& MCClary, D. O. (1982). Selection and fusion of auxotrophic protoplasts of Candida albicans. Antonie van Leeuwenhoek 48, 169 182.

FinChaM, J. R. S. \& Boylen, J. B. (1957). Neurospora crassa mutants lacking argininosuccinase. Journal of General Microbiology 16, 438-448.

Fournier, P., Provost, A., Bourguignon, C. \& HESLOT, H. (1977). Recombination after protoplast fusion in the yeast Candida tropicalis. Archives of Microbiology 115, 143-149.

Holliday, R. ( 1956). A new method for the identification of biochemical mutants of microorganisms. Nature, London 178, 987.

HowaRD, D. H. (1985). Nutrition, physiology, and metabolism of zoopathogenic fungi. In Fungi Pathogenic for Humans and Animals, part B, 2, pp. 4-56. Edited by D. H. Howard. New York: Marcel Dekker.

Hubbard, M. J., Poulter, R. T., Sullivan, P. A. \& SHEPHERD, M. G. (1985). Characterization of a tetraploid derivative of Candida albicans A TCC 10261. Journal of Bacteriology 161, 781-783.

J ACOBSON, E. S. \& AYERS, D. J. (1979). Auxotrophic mutants of Cryptococcus neoformans. Journa' of Bacteriology 139, 318-319.

KaKar, S. N. \& Magee, P. T. (1982). Genetic analysis of Candida albicans: identification of different isoleucine-valine, methionine, and arginine alleles by complementation. Journal of Bacteriology 1151 , $1247-1252$.

Kakar, S. N., Partridge, R. M. \& Magee, P. T. (1983). A genetic analysis of Candida albicans: isolation of a wide variety of auxotrophs and demonstration of linkage and complementation. Genetics 104, 241-255.
Lee, K. L., Buckley, H. R. \& Campbell, C. C. (1975). An amino acid liquid synthetic medium for the development of mycelial and yeast forms of Candida albicans. Sabouraudia 13, 148-153.

Lingens, F. \& Oltmanns, O. (1964). Erzeugung und Untersuchung biochemischer Mangelmutanten von Saccharomyces cerevisiae. Zentralblatt für Natürforschung 19b, 1058-1065.

ODDs, F. C. (1979). Candida and Candidosis. Baltimore: University Park Press.

Olaiya, F. A. \& Sogin, S. J. (1979). Ploidy determination of Candida albicans. Journal of Bacteriology 140 , 1043-1049.

Pesti, M. \& Ferenczy, L. (1982). Protoplast fusion hybrids of Candida albicans sterol mutants differing in nystatin resistance. Journal of General Microbiology 128, 123-128.

Poulter, R. T. M. \& Rikkerink, E. H. A. (1983). Genetic analysis of red, adenine-requiring mutants of Candida albicans. Journal of Bacteriology 156, 1066-1077.

Poulter, R., Jeffrey, K., Hubbard, M. J., ShepHERD, M. G. \& Sullivan, P. A. (1981). Parasexual genetic analysis of Candida albicans by spheroplast fusion. Journal of Bacteriology 146, 833-840.

Poulter, R., Hanrahan, V., Jeffrey, K., Markie, D., Shepherd, M. G. \& Sullivan, P. A. (1982). Recombination analysis of naturally diploid Candida albicans. Journal of Bacteriology 152, 969-975.

RHODES, J. C. \& Howard, D. H. (1980). Isolation and characterization of arginine auxotrophs of Cryptococcus neoformans. Infection and Immunity 27, 910 914.

SCHMit, J. C. \& Brody, S. (1976). Biochemical genetics of Neurospora crassa conidial germination. Bacteriological Reviews 40, 1-41.

Serlupi-Crescenzi, O., Kurtz, M. B. \& Champe, S. P. (1983). Developmental defects resulting from arginine auxotrophy in Aspergillus nidulans. Journal of General Microbiology 129, 3535-3544.

Whelan, W. L. \& Magee, P. T. (1981). Natural heterozygosity in Candida albicans. Journal of Bacteriology 145, 896-903.

Whelan, W. L \& Soll, D. R. (1982). Mitotic recombination in Candida albicans: recessive lethal alleles linked to a gene required for methionine biosynthesis. Molecular and General Genetics 187 , 477-485.

Whelan, W. L., Partridge, R. M. \& magee, P. T. (1980). Heterozygosity and segregation in Candida albicans. Molecular and General Genetics 180, 107113.

Whelan, W. L., Simon, S., Beneke, E. S. \& Rogers, A. L. (1984). Auxotrophic variants of Torulopsis glabrata. FEMS Microbiology Letters 24, 1-4. 